\title{
Facilitating Critical Thinking In An Introduction To Business Freshman Course
}

\author{
Cynthia M. Newman, Ph.D., Rider University, USA
}

\begin{abstract}
The current article presents an example of the development, implementation, and evaluation of a teaching intervention intended to facilitate student critical thinking through the integration of knowledge in an introductory business course. The intervention is grounded in the scholarship of teaching and learning literature. A discussion of the initial evaluation of the impact of the intervention on student learning is presented and directions for future research on the effectiveness of the intervention are discussed.
\end{abstract}

Keywords: Critical Thinking; Business Curriculum; Teaching Intervention

\section{INTRODUCTION}

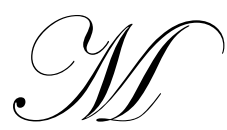

any college and university level instructors are trained to be experts in their disciplines, not to be experts in teaching. According to Bransford, et al., "Expert teachers know the kinds of difficulties that students are likely to face; they know how to tap into students' existing knowledge in order to make new information meaningful; and they know how to assess their students' progress." (Bransford, et al., 2000, 45) When it comes to effective teaching, Leamnson and others believe that "good teaching is a matter of doing the right things under appropriate circumstances, and that doing the right things is something that can be learned." (Leamnson, 1999, 52) The current article presents an example of an attempt to do the "right things" and reflect the manner of an "expert teacher" in terms of the development, implementation and evaluation of a teaching intervention that is grounded in the scholarship of teaching and learning literature and is intended to facilitate student critical thinking through the integration of knowledge in an introductory business course.

\section{THE TEACHING AND LEARNING CHALLENGE}

The course of focus in this article is a college-level introductory survey course in business targeted to firstyear business majors. Each of the topics covered in the course are mini-introductions to entire fields of study within business. For example, there is a unit on accounting, one on finance, one on economics, two on marketing, and four on management. As a result, many of the learning goals for the course are not content related. Specifically, the learning goals for the course are:

- $\quad$ To gain a general understanding of the business world, including the role of individuals within the firm as well as current issues such as competitiveness, ethics and globalization

- To develop a foundational understanding of the functional areas of business (finance, marketing and operations) as well as supporting areas (accounting, human resource management, information technology)

- $\quad$ To recognize and appreciate the inter-relationships among the functional and supporting areas of business

- $\quad$ To strengthen written and oral communication skills, teamwork skills and leadership abilities.

While the instructor makes a concerted effort when teaching this course, in particular, to emphasize during each class session how the topic of the day relates to other functional areas of business, formal assignments are also used to stress the integrated nature of business areas. The primary assignment used for this purpose is an industry portfolio term project that requires students to demonstrate their understanding not only of the various functional and supporting areas of business (learning goal two) but also of the inter-related nature of these areas in business practice (learning goal three). Each student must engage in the following steps in order to successfully complete the project: 
- $\quad$ Select an industry of interest

- Locate four recent articles appearing in The Wall Street Journal relevant to the selected industry and addressing the following functional and support areas of business: one management focused article, one marketing focused article, one finance or accounting focused article and one article from another functional or support area covered in the course (i.e., production \& operations, computer information systems, economics)

- Write four concept paragraphs, one for each article, that discuss the evidence present in the articles that supports the student's classification of each article. For example, if the student says an article is a marketing article, she should use the concept paragraph to describe what in the article is related to marketing.

- Write four integration paragraphs, one for each article, that discuss how the articles' content reflects the integrated nature of business functions. To assist students in writing these paragraphs, they are given guiding questions such as: how might other functional areas respond to the actions or decisions discussed in the article; how might other functional areas be affected by the actions or decisions discussed, and/or how might other functional areas have influenced the actions or decision discussed. For example, a marketing article that discusses the launch of a new product would be related to accounting in that the company will need to track expenses, to finance in that ROI goals would be set for the new product, and to human resource management in that the company may need to have hired employees to work on the development and launch.

While some students performed well on this term project designed to assess learning with respect to the outcome of integration, enough students did not (even in honors sections) that it was an area of concern to the instructor. The difficulty was primarily with the integration paragraphs. However, upon careful review of student responses across several semesters, the difficulty was not usually confined to just one business area; rather, the difficulty was present across all of the business areas included in the project. This suggested that student difficulty stemmed not from limited understanding of a particular topic, but rather from a limited understanding of the integrated nature of business, which represents a higher order of critical thinking. The remainder of this article discusses the planned teaching intervention intended to facilitate critical thinking in terms of integration of business knowledge, thereby resulting in demonstrated advances in learning the course material. Specifically, the intervention was intended to positively impact students' ability to think critically by recognizing how business decisions in one functional or support area may impact decisions and activities in another functional or support area.

\section{CHALLENGES FROM THE SCHOLARSHIP OF TEACHING \& LEARNING (SOTL) LITERATURE}

Two primary challenges from the SoTL literature about learning framed the planned intervention. The first was shared by Nelson (1999) and Brandsford, et al. (2000): design experiences for students that allow them to discover patterns and ways of organizing the "facts" of one's discipline into concepts that make sense. In order to do this effectively, the instructor must take the time to understand how novice learners see the facts, examples and experiences presented to them. In addition, assuming the instructor's goal is for students to learn how to think more like an expert in one's field than a novice over the course of the semester, the instructor needs to not only evaluate what students understand, but also evaluate what they do not understand and why. Subsequent assignments and learning experiences must then give students the opportunity not only to progress in the discovery and application of patterns and connections but also must provide students who have not yet meaningfully organized the facts of the field opportunities to do so.

The second challenge was articulated by Walvoord and Anderson (1998): offer a course that is assignmentcentered. As an introductory survey course that includes at least seven business disciplines, the introductory business course is a challenging course to make assignment-centered versus coverage-centered. However, holding exams aside, the remainder of the course assignments and the majority of in-class time in an assignment-centered course are designed, as Walvoord and Anderson say, to be focused on the "processing part of learning" $(1998,53)$. Of course, this requires that the instructor firmly communicates to students that the "first exposure part of learning" is their responsibility: carefully reading the text before coming to class, considering the reading review slides posted for each reading assignment, and completing other "homework" assignments. Making this shift is not comfortable for many instructors because, in order to do this, the instructor needs to sacrifice a lot of material and greatly reduce 
the span of coverage. However, the sacrifice often accomplishes a greater goal in that the course has a much sharper focus for the student and the instructor. In the course experience expounded upon below, the students' central learning objective and the instructor's central teaching objective was clearly articulated in both word and task to be "recognize and articulate the inter-relationships among the functional areas of business" once the teaching intervention was introduced.

\section{THE TEACHING INTERVENTION}

The teaching intervention intended to facilitate student ability to integrate knowledge involved two components, both of which provided scaffolding for student achievement of the desired central learning objective: development a modified version of a categorizing grid (Angelo and Cross, 1993, 160-163) and introduction of a practice assignment into the course at the mid-point that mirrored the term project assignment. The grid (Figure 1) lists the various functional and supporting areas of business across the top and notes prompts down the left side to encourage students to consider a business article from different perspectives - namely, what is directly referenced in the article with respect to various areas of business and what is implied. The practice exercise was divided into four parts in order to better assess the impact of the categorizing grid on student performance of the assigned task and also to allow students to see for themselves the thought process that is required to successfully complete the assignment. First, the students were asked to read a short article appearing in The Wall Street Journal and write the two paragraphs required in the term project. Second, students were introduced in class to the categorizing grid and were asked to re-read the article in order to populate the grid with examples of how the article references, either explicitly or implicitly, different areas of business. Third, students shared their completed grids with one another in small groups and were allowed to add or modify information on their grids based on the discussion with other students. Fourth, students were asked to revise their original paragraphs using the information from the categorizing grid. Specifically, one highly populated column on the grid would be selected as the business area to be discussed in the concept paragraph while the information in the remaining columns would be used to write the integration paragraph.

\section{EVALUATION \& RESULTS}

Students were asked to revise their paragraphs for the practice assignment based on the information in the categorizing grid using the track changes function of MS Word. This allowed them to see the contribution of the grid to the assignment as well as allowed the instructor a way to evaluate the impact of the intervention by comparing the before and after paragraphs using a Primary Trait Analysis (Walvoord and Anderson, 1998, 67-91). The traits included in the Primary Trait Analysis (PTA) were:

- $\quad$ Is the article appropriately classified?

- $\quad$ Does the concept paragraph include appropriate/accurate terminology and concepts from the business function under which the article is classified?

- Do the examples in the concept paragraph indicate a correct understanding of the business function?

- Is the article connected to multiple other business functions in the integration paragraph?

- Does the integration paragraph clearly articulate feasible connections between other business functions and the business function under which the article is classified?

- Are there any obvious connections to other business functions that are not included in the integration paragraph?

The three-point scale used was: not at all, somewhat, and yes. The same PTA was used to evaluate the concept and integration paragraphs submitted by the students for the final term project. In addition to the instructor evaluation of the impact of the intervention on the central learning objective using the PTA, students were asked to evaluate the term project and the modified categorizing grid via an additional set of questions on the course evaluation form. 


\begin{tabular}{|c|c|c|c|c|c|c|c|}
\hline & Accounting & $\begin{array}{l}\text { Computer/ } \\
\text { Management } \\
\text { Info. Systems }\end{array}$ & Economics & Finance & Management & Marketing & $\begin{array}{l}\text { Production \& } \\
\text { Operations }\end{array}$ \\
\hline $\begin{array}{l}\text { Explicit } \\
\text { Article } \\
\text { Reference \#1 }\end{array}$ & & & & & & & \\
\hline $\begin{array}{l}\text { Explicit } \\
\text { Article } \\
\text { Reference \#2 }\end{array}$ & & & & & & & \\
\hline $\begin{array}{l}\text { Implication } \\
\# 1\end{array}$ & & & & & & & \\
\hline $\begin{array}{l}\text { Implication } \\
\# 2\end{array}$ & & & & & & & \\
\hline $\begin{array}{l}\text { Implication } \\
\# 3\end{array}$ & & & & & & & \\
\hline
\end{tabular}

Figure 1: Business Functional and Support Areas Categorizing Grid

As indicated by the responses to the supplemental questions included on the course evaluation form as displayed in Figure 2, students received both the project and the categorizing grid very well. A few students, in the "additional comments" section of the course evaluation form, actually thanked the instructor for providing the categorizing grid and the practice assignment, even though it was work that "didn't count". In addition, the grade distributions for the concept and integration paragraphs that were part of the final project were encouraging. (See Figure 3) Surprisingly, the class as a whole performed better on the more challenging of the two paragraphs, the integration paragraphs. This may be a result of the strong emphasis that was placed during the semester on the integration of knowledge across business subjects.

Evaluation of the Project (5 point scale 1=strongly disagree to 5=strongly agree)

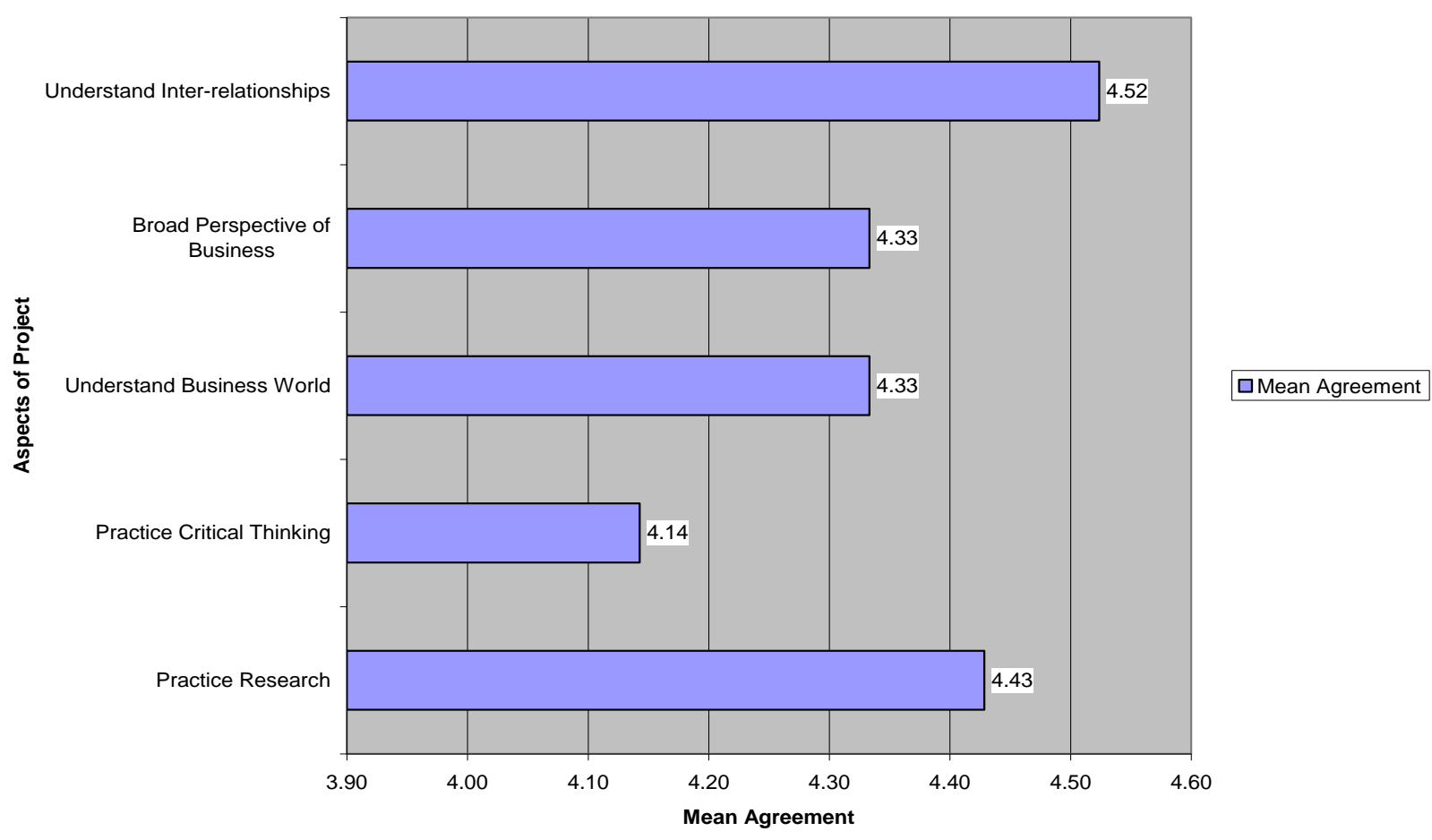

Figure 2: Student Evaluations of the Term Project and the Categorizing Grid 


\section{Concept Paragraph Grade Distribution}

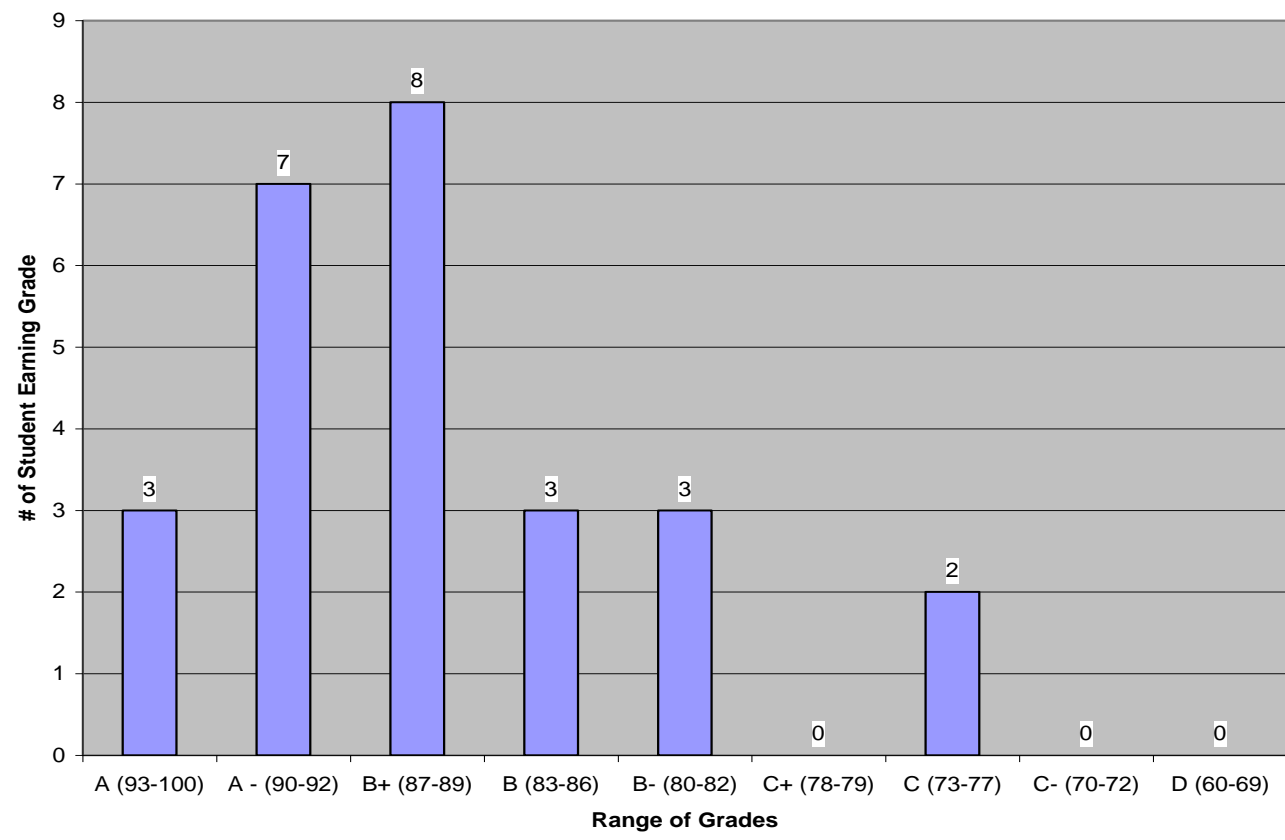

$\square \#$ of Grades in Range

Integration Paragraph Grade Distribution

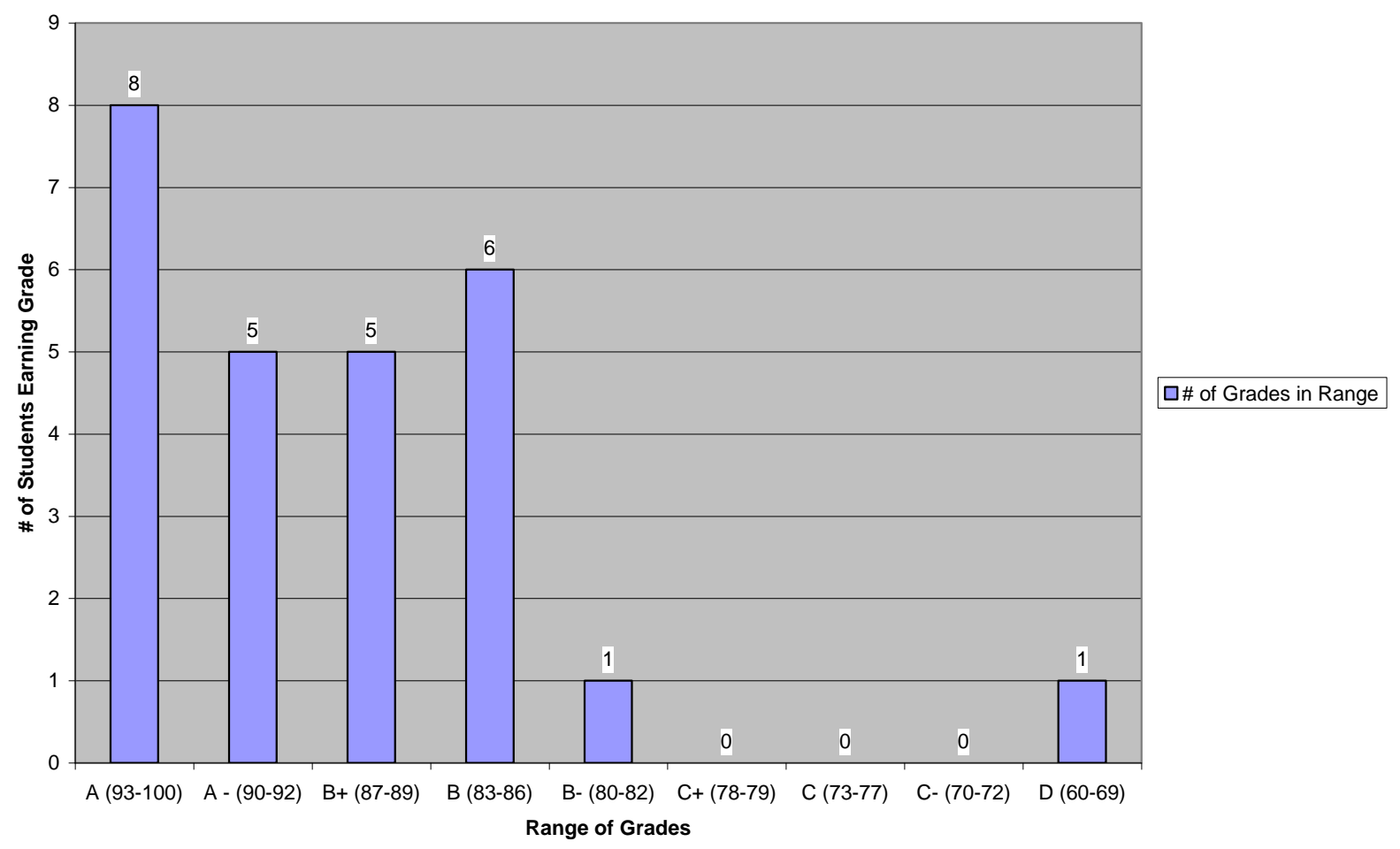

Figure 3: Term Project Grade Distribution 
The PTA of the paragraphs written before and after the introduction of the categorizing grid and of the final project paragraphs yielded results that indicated a positive contribution of the intervention to student achievement of the central learning objective. When using the PTA to evaluate the before and after concept paragraphs from the practice assignment, the results indicated improvement in terms of the inclusion of relevant examples and terminology. In comparing the practice assignment integration paragraphs before and after the introduction of the categorizing grid, improvement was seen in the ability of students to identify multiple connections to other business functions and in the articulation of connections to other business areas. Fewer of the integration paragraphs after the introduction of the grid omitted obvious connections to other business functions than was the case in the integration paragraphs written without the benefit of the grid. The Primary Trait Analysis of the final projects indicated satisfactory performance (ratings of somewhat or yes) on most of the six areas. The area in which the students needed the most improvement was including appropriate reference to terminology and concepts from the business function under which the article was classified in the concept paragraphs. While disappointing, this result was not unexpected given that the decision was made to sacrifice some course content in moving from a coverage-centered to an assignment-centered course.

\section{CONCLUSIONS \& FUTURE RESEARCH}

Through this intervention the instructor learned that freshman students are capable of mastering the critical thinking task that was expected of them as per the course learning objectives. In addition, when the instructor trades the mentality of "I have to get through all of this material" for a deliberate focus on a central learning objective, the students are less overwhelmed by the course and the instructor can have more confidence that learning of a valuable tool - namely, how to think critically by integrating knowledge - has been realized. Finally, the intervention also made apparent the truth of the directives in the SoTL literature that students need to not just be shown what mastery of the task looks like but also need to be given practice performing the required task as well as to be given support in performing the task that makes the steps as explicit and discrete as possible. To be effective, teaching interventions do not necessarily need to be complicated or creative; however, they should be grounded in tested and enduring theories and methods of learning.

The primary focus for future research concerning the above discussed intervention should focus on two areas, sequentially: validating the impact of the intervention on student learning and, if validation is evidenced, determining whether there are long-term benefits of the intervention as students move into upper-level business core courses. From the introductory business course, students move into a series of courses that provide function specific, semester-long introductions to the various areas of business covered in the introductory freshman course. These areas include: courses in accounting, economics, finance, management, management information systems, marketing, production and operations, and the social and legal environment of business. Students who have understood the integrated nature of business functions and who have been exposed to the basic tenets of each business area in the introductory course should have a "big picture" framework into which they can sort the key concepts covered in these various upper level business core courses. The capstone course for all business majors is a course in Strategic Management where the integration of business functions is once again a primary focus. From a curriculum perspective, the expectation in this capstone course is that students who came to understand the concept that business functions are integrated as freshman are now, at the end of their academic careers, able to effectively apply that concept to real business decision making and analysis situations. One approach would be to compare the performance in the capstone course of students who experienced the introductory business course with the above discussed intervention to that of two other groups of students: those who did not have an introductory business course and those who had an introductory course without the intervention focused on integrating knowledge. A favorable outcome for such research would lend further support to the intervention as a valuable learning experience that facilitates critical thinking through the integration of knowledge not only in the short-term but also over the long-term. 


\section{AUTHOR INFORMATION}

Cynthia Newman received a Ph.D. (1998) in higher education administration from the University of Pennsylvania and an M.B.A. and B.S. in business administration from Rider University. She currently is Director of the Center for International Business and an Associate Professor of Marketing in the College of Business Administration at Rider University. In addition, she is on the leadership team for the Executive Center for Education and Development. Her areas of teaching expertise include strategic marketing planning and international marketing. Her research interests are in the areas of positioning and the scholarship of teaching and learning. E-mail: cnewman@ rider.edu

\section{REFERENCES}

1. Angelo, T. A. \& Cross, K. P. (1993). Classroom Assessment Techniques: A Handbook for College Teachers. Jossey-Bass.

2. Bransford, J. D., Brown, A. L. \& Cocking, R. R. (Eds.). (2000). How People Learn: Brain, Mind, Experience \& School: Expanded Edition. Washington, DC: National Academy Press.

3. Leamnson, R. (1999). Thinking About Teaching and Learning: Developing Habits of Learning with First Year College and University Students. Sterling, VA: Stylus Publishing.

4. Nelson, C. (1999). On The Persistence Of Unicorns: The Tradeoff Between Content And Critical Thinking Revisited. In B. A. Pescosolido \& R.Aminzade, (Eds.). The Social Worlds of Higher Education. Los Angeles, CA: Pine Forge Press.

5. Walvoord, B. E. \& Anderson, V. J. (1998). Effective Grading: A Tool for Learning and Assessment. San Francisco, CA: Jossey-Bass. 
NOTES 